\title{
ВЕЛИКОБРИТАНИЯ И ЕВРОПЕЙСКИЙ СОЮЗ: ДОЛГАЯ ИСТОРИЯ РАЗВОДА. СТАТЬЯ 2. СЛОЖНЫЙ ПАРТНЁР
}

\begin{abstract}
Аннотация. В статье исследуется история взаимоотношений Великобритании и Европейского союза с 1950-х годов по настоящее время. Проанализировано, как системные факторы - специфическое отношение Великобритании к дизайну, предназначению и будущему $\mathrm{EC}$, специфическое понимание базовых ценностей интеграции - определяли стратегию и тактику европейской политики Лондона. Показано, как нарастало неразрешимое противоречие между стремлением Лондона обеспечить независимость от ЕС и желанием влиять на политику ЕС. Обосновано, что основные параметры политики Лондона в отношении ЕС определяются особенностями британской идентичности. Укоренённое в истории противостояние с континентальной Европой трансформировалось в противостояние "гегемонии Евросоюза".

Ключевые слова: Европейский Союз, Великобритания, брекзит, европейская интеграция, идентичность.

В первой части нашего исследования [Кавешников, 2018] мы показали, что на протяжении всего периода членства в ЕС (и даже до вступления), европейский вопрос дестабилизировал политическую систему Великобритании, порождал расколы в обществе, между партиями и внутри партий. Даже британские сторонники активного участия в деятельности ЕС имели специфические взгляды на желаемый дизайн, объём полномочий и направление развития ЕС. В политической элите, а последние 20 лет в широких общественных кругах было сильно влияние евроскептичных сил.

Не удивительно, что политика Великобритании в ЕС существенно отличалась от действий большинства других стран. "Великобритания, будучи в Европейском Союзе, никогда не чувствовала себя как дома" [May, 2017]. В то время как сама Великобритания испытывала дискомфорт от необходимости жить по правилам ЕС, другие государства-члены ощущали не меньший дискомфорт от действий Лондона.
\end{abstract}

(C) Кавешников Николай Юрьевич - кандидат политических наук, заведующий кафедрой интеграционных процессов МГИМО МИД России. Адрес: 119454, Россия, Москва, пр-т Вернадского, 76; ведущий научный сотрудник Института Европы РАН. Aдpec: 125009, Россия, Москва, ул. Моховая, д. 11-3. E-mail: n.kaveshnikov@inno.mgimo.ru

DOI: http://dx.doi.org/10.15211/soveurope620181829 
Во второй части работы мы исследуем особенности политики Великобритании в ЕС, анализируем, как различное понимание базовых ценностей интеграции между Великобританией и её континентальными партнёрами порождало разногласия по широкому кругу текущих вопросов. Мы также хотим показать, как нарастало неразрешимое противоречие между стремлением Лондона обеспечить независимость от ЕС и желанием влиять на политику ЕС. В завершение мы постараемся доказать, что основные параметры политики Лондона в отношении ЕС определяются особенностями британской идентичности.

\section{Иное видение интеграции}

Хотя в целом ряде сфер и связанных с деятельностью ЕС вопросов Великобритания играла значимую конструктивную роль, всё же более заметны были иные особенности ее политики. Великобритания регулярно тормозила инициативы углубления интеграции, параллельно добиваясь для себя исключений и особый условий (не)участия в отдельных политиках ЕС [подробнее см. Кавешников, Матвеевский, 2017: 289-297].

Системная причина этого в том, что отношение Великобритании к дизайну, предназначению и будущему Евросоюза традиционно отличалось от мнения, доминировавшего среди континентальных членов ЕС. Преобладающая часть британского общества и политических элит отрицала ряд базовых ценностей европейской интеграции, значимых для мейнстрима континентальной политической элиты: общая судьба, солидарность, опора на коммунитарный метод, постепенное, но неуклонное углубление интеграции, политическое значение экономической интеграции и продвижение к политическому союзу. Ключевое значение для понимания политики Лондона имеют три отличия.

Экономика versus политика. Британцы хотели экономической интеграции и свободной торговли, но не были готовы к интеграции политической.

Еще в 1950-е годы, отказавшись от участия в ЕЭС, Лондон инициировал учреждение Европейской ассоциации свободной торговли (ЕАСТ), которая открыто позиционировалась как противовес ЕЭС. Позднее вопрос вступления в ЕЭС обсуждался преимущественно в экономических категориях. В своих мемуарах М.Тэтчер пишет о "господствовавшем убеждении", что вступление “было необходимым с точки зрения британских национальных, особенно экономических, интересов" [Тэтчер, 2003: 398].

В ситуации неясной, а точнее, не до конца проговоренной finalité интеграционного процесса, Великобритания "постоянно недооценивала амбиции своих партнёров по созданию и политического, и экономического союза" [Cooper, 2012: 1200]. Тони Блэр в одной из своих речей обратил внимание на то, что политикам обеих партий десятилетиями не удавалось понять возникающую реальность европейской интеграции, - “мы говорили, что этого не будет... что это не будет работать, что нам это не нужно", мы говорили это и в 1950 -е, и в 1970-е, и 1990-е по поводу введения евро [Blair, 2001]. Мощная федералистская динамика развития EC в 1990-е годы “открывает глаза” британской элите. В 2002 г. М. Тэтчер пишет: “[Мы] были немного наивными... Оглядываясь назад, понимаешь: Инок Пауэлл, твердивший, что вступление в Общий рынок влечёт за собой в конечном итоге не решение эко-

Современная Европа, 2018, №6 
номических проблем, а недопустимую потерю суверенитета, был абсолютно прав... [Идет] строительство нового европейского сверхгосударства" [Тэтчер, 2003: 399, 390].

С начала 2000-х британцы осознают, что они все менее способны контролировать (то есть тормозить) развитие политической интеграции. Камерон заявлял, что Евросоюз движется в направлении, на которое британцы никогда не давали согласия, что всё новые договоры "меняют баланс между государствами-членами и ЕС" (Cameron, 2013). Звучали и обвинения в адрес европейских лидеров. "Многие годы континентальные лидеры отрицали свои федеральные амбиции, но их действия приближали нас к [федерации]... Мы не знаем, где остановится рост Европы (more Europe)" [Major, 2013]. Чем дальше уходила вперед “политическая Европа", тем больший дискомфорт ощущали британские политики.

Наднациональность versus межправительственный подход. Лондон последовательно делал все возможное, чтобы минимизировать элементы наднациональности, и предпочитал видеть в Евросоюзе систему межправительственного сотрудничества.

В своих мемуарах Жан Монне справедливо отмечал, что институты ЕЭС “по видимости были экономическими и техническим, но в действительности - политическими" [Монне, 2001: 525]. К моменту вступления Великобритании институты ЕЭС были существенно ослаблены из-за Люксембургского компромисса, по сути торпедировавшего коммунитарный (наднациональный) метод принятия решений, и сохранявшейся в Париже приверженности концепции “Европы отечеств".

Настоящая битва за институты началась позднее. В 1980-е годы М. Тэтчер боролась против реформы ЕЭС. В начале 1990-х на переговорах о Маастрихтском договоре Великобритания добилась права не вводить евро и много сделала для того, чтобы и вторая, и третья опоры политического союза имели межправительственный характер. Более того, именно Великобритания настояла на создании в Евросоюзе структуры “трех опор”, хотя “большинство стран-членов склонялись к более интегрированной структуре, которую образно называли не "храм с тремя опорами", а “дерево с тремя ветвями"”. Пожалуй, лучше всех отношение британцев к любым элементам наднациональности сформулировала М. Тэтчер в выступлении в палате общин 30 октября 1990 года: "На днях господин Делор сказал на пресс конференции, что он хочет видеть Европейский парламент демократическим собранием Сообщества, Комиссию - его исполнительным органом, а Совет министров - сенатом. Нет! Нет! Нет!" [Грант, 2002: 239].

Из всех британских лидеров лишь Тони Блэр придерживался прагматического подхода к организационному устройству ЕС. Разумеется, и он также отвергал “федеральное супергосударство" и требовал гарантий против "централизации". Однако при этом он понимал суверенитет не как “способность одной страны сказать "нет", но как возможность максимизировать силу и влияние нашей нации в вопросах бизнеса, торговли, внешней политики, обороны...”. А изоляция, по его мнению, приведет к обратному, оставив Великобританию "единоличным хозяином съеживающейся сферы влияния" [Blair, 2001].

Альтернативу наднациональности британские лидеры формулировали поразному, но суть всегда была одна и та же: межправительственное сотрудничество. М. Тэтчер в 1988 г. заявляет: “Добровольное и активное сотрудничество между не-

Современная Европа, 2018, №6 
зависимыми суверенными государствами - это лучший способ построить успешный Европейский Союз... это не требует централизации власти в Брюсселе" [Thatcher, 1988]. Через десять лет лейбористы в своем предвыборном манифесте повторяют: "Наше видение Европы - это альянс независимых наций, выбирающих сотрудничество чтобы достичь целей, которые они не могут достичь поодиночке"1. Этот тезис звучит снова и снова, и вот спустя ещё двадцать лет Д. Кэмерон в очередной раз декларирует: "Упомянутое в Римском договоре обязательство строительства все более тесного союза не должно более применяться к Британии... Мы верим в гибкий союз свободных государств-членов ... работающих вместе в духе сотрудничества" [Cameron, 2015].

Великобритания всегда поддерживала расширение ЕС, рассчитывая, что это замедлит углубление интеграции. Еще в 1977 г. Дж. Каллаган писал об этом в открытом письме генеральному секретарю Лейбористской партии, отстаивая идею вступления Греции, Испании и Португалии [George, 2000: 16]. В 1990-е годы эта логика стала одним из важнейших факторов, определивших позицию Великобритании по вопросу расширения на восток.

Свобода предпринимательства versus государственное регулирование. Будучи сторонником экономического либерализма, Лондон всячески препятствовал развитию в ЕС регуляторных политик, разработке общий стандартов или иных мер гармонизации, особенно если ЕС ставил своей целью не просто экономическое регулирование, а повышение уровня социальной защиты ${ }^{2}$.

В 1977 г. премьер-министр Джеймс Каллаган (лейборист!) говорил об “опасности... сверхцентрализованного, сверхбюрократизированного и сверхгармонизированного Сообщества" [Tsoukalis, 1979: 38]. Д. Хау в середине 1980-х гг., призывая Сообщество активнее заняться повышением экономической конкурентоспособности, полагал, что ЕЭС должен “генерировать богатство, а не только распределять его" [Howe, 1984: 190]. При этом лидеры консерваторов того периода искренне верили, что отцы-основатели ЕЭС разрабатывали Римский договор как “договор экономического либерализма" [Тэтчер, 2003:402; Howe, 1984: 191], а возрастающую регуляторную активность Еврокомиссии считали искажением этого замысла. В тот период британцы искренне не понимали, что для большинства их европейских партнёров Единый рынок - это не самоцель, а часть пакета, который в перспективе должен был включить социальное измерение и единую валюту.

Позиция Лондона была чрезвычайно последовательной, основные критические тезисы в адрес ЕС повторяются как минимум последние тридцать лет. "Мой третий принцип в том, что Сообщество должно “поощрять предприятия", - говорит М. Тэтчер в 1988 г. "Мой первый из пяти принципов - конкурентоспособность”, эхом отзывается Д. Камэрон в 2013 г. "Центральное планирование и детальный контроль не работают”, - продолжает Тэтчер. “Сложные правила, ограничивающие

1 Labour Party's 1997 Manifesto "Britain will be better with new Labour". Available at http://www.politicsresources.net/area/uk/man/lab97.htm Assessed 31 July 2018.

2 Разумеется, государственное регулирование играет заметную роль и в британской экономике. Однако существующий в Великобритании баланс между свободой предпринимательства и государственным регулированием принципиально отличается от ситуации в континентальных странах Западной Европы.

Современная Европа, 2018, №6 
наши рынки труда... излишнее регулирование...”, - соглашается Камерон. [Thatcher, 1988; Cameron, 2013; Cameron, 2015]. Тони Блэр, будучи социалистом, не акцентировал эти вопросы, но всё же отмечал излишнюю забюрократизированность ЕС и излишнее регулирование.

Характерно, что в сфере единого рынка Лондон последовательно поддерживал все действия ЕС по дерегулированию экономики, в частности, либерализацию сектора телекоммуникаций, авиатранспорта, энергетического рынка, рынка финансовых услуг, и еще более последовательно возражал против социального законодательства, аграрной политики ЕС и попыток коммунитаризации налоговой системы стран-членов. В основе такого подхода лежало глубокое убеждение (разделяемое и консерваторами, и лейбористами), что англо-саксонская модель экономики принципиально лучше европейской социальной модели.

\section{Отсутствующий всегда опаздывает}

Вследствие стратегического просчёта 1950-х гг. Великобритания была вынуждена присоединиться к Сообществу, которое уже имело сформировавшиеся институты, полномочия и инструменты, идеологию и динамику развития. Три основных достижения ЕЭС до вступления Великобритании - бюджет, общая торговая политика и общая сельскохозяйственная (и рыболовная) политика, - стали основными камнями преткновения. В процессе вступления страна-кандидат ничего не может изменить в имеющемся acquis, переговоры могут идти только о переходных периодах. Единственная рациональная стратегия - это вступить в ЕС, а потом, уже в качестве полноправного члена, стремиться изменить Евросоюз или условия своего членства. Именно эту стратегию использовала Великобритания на протяжении десятилетий, благо имеющиеся у страны экономические и политические ресурсы давали ей возможность попытаться изменить траекторию движения ЕС. Примеры использования этой стратегии мы видим в истории разработки практически каждого нового договора о реформах ЕС, в повторяющихся каждые семь лет переговорах о бюджете, бесконечных спорах о сельскохозяйственной политике, при принятии системообразующих документов в отдельных отраслях политики.

В последнее десятилетие Лондон пытался свои индивидуальные исключения представить как новый базовый принцип функционирования всего Евросоюза. Под лозунгом “Один размер не подходит для всех" [Cameron, 2015], предлагалось интерпретировать созданные механизмы гибкой интеграции как возможность всех стран пользоваться различными opt-outs, хотя магистральное направление развития гибкой интеграции - это создание структур постоянного сотрудничества - групп, реализующих различные проекты углубления интеграции [Бабынина, 2012]. При этом чем более глубокой становилась интеграция в ЕС, тем более системного пересмотра условий членства Лондона требовали британские политики.

Выбранная Великобританией стратегия вела к ослаблению её способности влиять на политику и развитие ЕС, со временем Лондон приобрёл репутацию "сложного партнёра" и всё чаще оказывался в изоляции. На саммите в 1990 г. Джон Мэйджор, чтобы не допустить создания евро, предложил альтернативный план - “твёрдый экю”, который стал бы параллельной валютой наряду с национальными. Предложение было отвергнуто, а Ф. Миттеран в личной беседе сказал

Современная Европа, 2018, №6 
Мэйджору: "Хорошая идея - плохая страна" [Major, 2013]. Великобритания стала в ЕС “плохой страной”, с середины 1990-х гг. её всё чаще называли “неполным” членом Евросоюза.

Начало работы Еврогруппы ${ }^{1}$ в конце 1990 -х гг. сразу же вызвало раздражение Лондона, его беспокоила практика Еврогруппы обсуждать вопросы экономической политики за день до заседания совета Экофин, где представлены все страны ЕС. Постепенный переток к Еврогруппе полномочий макроэкономического регулирования привел к тому, что Еврогруппа “де факто определяет экономическую повестку дня в еврозоне" [Европейская интеграция, 2016: 207], а значит, и в целом в ЕС, а также во все большей степени влияет на стратегические решения о будущем ЕС. Неспособность влиять на дискуссии в рамках Еврогруппы и усиливающаяся изоляция вызывали у Великобритании все большее неприятие. А попытки Лондона влиять на функционирование ЭВС вызывали растущее раздражение лидеров континентальной Европы, которое всё чаще прождало открытые скандалы. К примеру, на пресс-конференции после саммита в октябре 2011 г. Н. Саркози заявил: "Нам надоело, что вы (Д. Кэмерон. - Н.К.) критикуете нас и учите, что мы должны делать. Вы говорили, что ненавидите евро, а теперь вы хотите участвовать в наших встречах (лидеров Еврогруппы. - Н.К.)... Вы упустили хорошую возможность промолчать"2.

Неразрешимое противоречие европейской политики Великобритании заключалось в том, что, получая желаемые исключения, Лондон всё чаще оказывался вынужден “молчать", но не мог "молчать”, поскольку даже в этих сферах решения ЕС во все большей степени затрагивали экономические и политические интересы страны. Это противоречие ощущали все ответственные британские политики, но лишь Тони Блэр рискнул предложить очевидный выход - присоединение к еврозоне. Однако ему не удалось получить поддержку политической элиты и обеспечить благоприятные условия для проведения референдума о единой валюте.

Все прочие лидеры, особенно консерваторы, продолжали искать квадратуру круга: как, не входя в зону евро, участвовать в её управлении. "Если ЕС превратится в “клуб единой валюты”, где все прочие отодвигаются в сторону и отстраняются от управления, такой клуб не для нас", - декларировал Камерон [Cameron, 2015]. Однако именно еврозона постепенно становилась ключевым экономическим проектом ЕС и каркасом для экономического управления.

\section{Идентичность формирует политику}

Во взаимоотношениях Лондона и “Европы Евросоюза” было много экономики, но было мало солидарности и единства на уровне идентичности, говоря метафорически, не было любви и ощущения единой семьи.

Чужак. Знаменитая фраза У. Черчилля "Мы с Европой, но мы не часть Европы” отражает общий подход британцев к Европейскому Союзу. Впервые эту позицию он сформулировал в статье в газете "Сатедей Ивнинг Пост" (The Saturday Evening

\footnotetext{
${ }_{1}^{1}$ Страны EC, перешедшие на единую валюту.

${ }^{2}$ Stratton A. and Gow D. Nicolas Sarkozy tells David Cameron: shut up over the euro. The Gardian, 23 October 2011. https://www.theguardian.com/politics/2011/oct/23/cameron-sarkozyeuro-debt-crisis_Accessed 31 July 2018.

Современная Европа, 2018, №6
} 
Post) от 15 февраля 1930 г. [Churchill, 1930], а впоследствии повторял неоднократно. Вот и в своей знаменитой речи в Цюрихе, призывая к созданию Соединённых штатов Европы”, У. Черчилль в завершение сказал: “Великобритания, Британское содружество наций, могущественная Америка и Советская Россия... должны стать друзьями и покровителями новой Европы”, тем самым очевидно отделяя Великобританию от “новой Европы” [Churchill, 1946].

Островной менталитет всегда был символом культурных различий между Великобританией и континентальной Европой. В последние десятилетия XX века именно континентальная "Европа Евросоюза" стала играть классическую роль внешнего “другого”, на оппозиции к которому строится собственная идентификация [Daddow, 2012; Gifford, 2006; Wallace, 1991]. Тони Блэр в 2001 г. с сожалением отмечал, что Лондон всегда проявлял неуверенность (half-hearted) в партнёрстве с EC. Тереза Мэй уже после референдума о брекзите констатировала: "Великобритания, будучи в Европейском Союзе, никогда не чувствовала себя как дома... Европейский союз никогда не был для нас неотъемлемой частью нашей истории, каким он был для многих других в Европе" [May, 2017].

Характерно, что, выступая против мигрантов, британцы (и политики, и простые люди) не делают большого различия между гражданами других стран ЕС и приезжими из стран Азии или Африки. Даже в политическом дискурсе используется термин “миграция из ЕC" [Cameron, 2015], а не “свободное передвижение”. Островной менталитет способствует тому, что политика ЕС воспринимается не как сумма общих усилий, а как некое внешнее вмешательство, которое приходится терпеть либо от него защищаться. Аналогично проблемы континентальной Европы в Великобритании воспринимаются как чужие. К примеру, в 2011 г. Д. Кэмерон заявил, что больше не будет оказывать помощь Греции через структуры ЕС, поскольку это проблемы зоны евро, в которую Великобритания не входит [Дилеммы Британии, 2014: 329].

Отсутствие эмоциональной связи, ощущения единой семьи породило прагматический подход Лондона. Одними и теми же словами лидеры консерваторов формулируют простую мысль о том, что Евросоюз - не самоцель, а средство достижения целей [Thacher, 1988; Cameron, 2013]. Это резко контрастирует с идеологическим, даже визионерским отношением французских, германских и других континентальных лидеров ЕС.

Чужая "империя". В определённой степени такое отношение к ЕС строилось на геополитических соображениях. Изначально позиция Великобритании "вне Европы”, а вернее, “над Европой” была основана на концепции “трёх сфер”, предложенной У. Черчиллем. Первая сфера - Соединённые Штаты, вторая сфера - Британское содружество наций, третья сфера - объединённая Европа. Позднее практически все лидеры заявляли, что у Великобритании есть много ролей на международной арене и различные интересы [Wall, 2008].

Впрочем, этот тезис справедлив для многих европейских стран, особенно для крупных. Однако в отличие от них Великобритания никак не могла признать, что центральное значение для нее имеет Евросоюз, поскольку ощущала, что "не до конца принадлежит ему" [Cooper, 2012: 1200].

Решающим фактором, формировавшим отношение британского общества к ЕС, всегда была “глубинная” британская (англо-саксонская) идентичность, которая “так

Современная Европа, 2018, №6 
же стара, как Шекспир, вызревала через опыт английской гражданской войны и битвы против угрозы католического абсолютизма, сначала против Испании, а потом против Франции: свободная Англия, противостоящая несвободному континенту" [Wallace, 1991]. Один из важнейших элементов исторического опыта Великобритании - это борьба против чьей-либо гегемонии в континентальной Европе, "В течение столетий мы боролись за то, чтобы уберечь Европу от подчинения доминированию одной державы” [Thacher, 1988].

В этой модели идентичности Европейский Союз идеально подошел на роль гегемона континентальной Европы. Рациональное сознание подталкивало к развитию сотрудничества с EC, а коллективное бессознательное требовало разрушить наднационального гегемона или как минимум обеспечить собственную независимость от него. С. Джордж показал, что в британском политическом дискурсе о ЕС очень большое место занимают такие идеи, как: Франция и Германия доминируют в ЕС и используют его чтобы доминировать над Британией; Франция пытается через ЕС навязать Британии свою правовую систему; французская концепция демократии чужеродна британцам; Германия стремится сделать ЕС авторитарной организацией. И это не говоря уже о многочисленных упоминаниях о “норманнском иге”, Наполеоне и Гитлере [George, 2000: 18-19].

Неудивительно, что "все британские правительства активно участвовали в европейской интеграции с целью защитить интересы Британии" [Oliver, 2015: 78] это очень характерная оценка: не развивать европейскую интеграцию, не содействовать эффективной реализации функций $\mathrm{EC}^{1}$, a “защищать” интересы Лондона от некоего внешнего, потенциально негативного воздействия.

“Мы хотим быть в Европе, но не хотим, чтобы Европа управляла нами", - этот лозунг, пронизывавший всю европейскую политику Лондона, был попыткой синтеза позиции сознания и подсознания. По существу, это означало желание одновременно быть в Европе и вне Европы.

Претензия на лидерство. При этом Великобритания хотела не просто “быть в Европе”, она хотела управлять Европой. В начале 1960-х гг. госсекретарь США Дэн Ачесон сказал: "Великобритания потеряла Империю и ещё не нашла [новую] роль [в мире]" [Acheson, 1963]. Великобритания до сих пор переживает травму потери империи. В попытках найти себе новую роль Великобритания ходила по замкнутому кругу - она искала новую империю, в которой могла бы быть лидером. Она воспринимала Европейский Союз как чужака, потому что это была “чужая империя". Чтобы воспринимать ЕС как “своего”, Великобритания должна была сделать его своим в прямом смысле слова. Ибо британцы способны в полной мере считать своим только то сообщество, которое они возглавляют. Но как это сделать, когда в ЕС присутствуют признанные лидеры и они двигают весь Евросоюз в неприемлемом для Британии направлении? Ответ очень прост: найти союзников и реформировать ЕС, придав ему отвечающий интересам Лондона дизайн.

\footnotetext{
${ }^{1}$ Хотя, безусловно, Великобритания активно участвовала в ряде сфер деятельности ЕС.

${ }^{2}$ Conservative party's 1997 Manifesto "You can only be sure with the Conservatives". Available at http://www.conservative-party.net/manifestos/1997/1997-conservative-manifesto.shtml Assessed 31 July 2018
} 
Об этом пятнадцать лет назад говорил Тони Блэр: “Мы должны быть лидером, чтобы изменить Европу в желаемом направлении" [Blair, 2001]. Уже не занимая государственных постов, Дж. Мэйджор в 2013 г. задается вопросом: как Великобритания “может добиться лидирующей роли?” И сам себе откровенно отвечает, что следует "искать союзников и добиваться реформирования ключевых политик EC". Далее он перечисляет страны, не входящие в зону евро, особенно акцентируя страны Восточной Европы - "Мы естественные союзники для их амбиций и для реформ, которых они добиваются” [Major, 2013]. Ему вторит Д. Кэмерон: "Нам нужна британская модель членства, которая будет пригодна для Британии и для всех других нечленов зоны еврозоны" [Cameron, 2015].

Вот суть стратегии Лондона на протяжении двух последних десятилетий: возглавить всех несогласных с существующим институциональным дизайном Евросоюза, изменить Евросоюз согласно своим предпочтениям и обеспечить себе место лидера (одного из лидеров).

А каков отвечающий интересам Лондона дизайн ЕС?

В области экономики это Евросоюз, “важнейшей основой [которого] является единый рынок, а не единая валюта" [Cameron, 2013]. Такое понимание сути Евросоюза превращает Великобританию из важного, большого, но все-таки аутсайдера в одного из ключевых членов.

С политической точки зрения - это межправительственная организация, “добровольное и активное сотрудничество между независимыми суверенными государствами” о котором говорила ещё М. Тэтчер [Thatcher, 1998]; “союз наций, работающих в более тесном сотрудничестве, а не федеральное супергосударство, растворяющее национальную идентичность" [Blair, 2001]; Евросоюз, “который признаёт различное видение (будущего. - Н.К.) своих стран-членов" [Cameron, 2015], и “в котором государства-члены объединены гибким сотрудничеством при уважении их национальных различий” [Cameron, 2013].

Есть только один способ “быть в Европе”, чтобы Европа “не управляла нами”, это самим управлять Европой, определяя дизайн Евросоюза и направление его развития. Это единственный вариант, который мог устроить Великобританию. Однако большинство континентальных членов ЕС имели другой взгляд на настоящее и будущее Евросоюза.

Будучи не в состоянии разделить устремления большинства континентальных партнёров, Лондон последовательно тормозил интеграционную динамику или, не имея возможности заблокировать новые проекты, добивался всё новых исключений. Разумеется, в ряде сфер деятельности ЕС Лондон проводила проактивную политику. Но в целом Великобритания заслуженно заработала имидж сложного партнёра.

Дискомфорт, который Лондон испытывал в связи с членством в ЕС, был связан с тремя стратегическими расхождениями по вопросам интеграционного строительства: нежелание политической интеграции, резкое неприятие наднациональных/федеративных элементов, конфликт между британской моделью свободного рынка и континентальной моделью социального государства.

Современная Европа, 2018, №6 
Со временем интеграция в ЕС углублялась, а позиция британского истэблишмента эволюционировала в обратном направлении. Расхождение во взглядах становилось всё шире; оно затрагивало и вопросы стратегического развития, и ежедневное функционирование ЕС.

В основе отношения Великобритании к ЕС лежали глубинные особенности британской идентичности. Укоренённое в истории противостояние с континентальной Европой трансформировалось в противостояние “гегемонии Евросоюза". Особый взгляд на евроинтеграцию и многочисленные исключения ослабляли влияние Лондона в Евросоюзе и всё чаще вели к его изоляции. Однако для Лондона было неприемлемо участие без лидерства, без возможности влиять на стратегические решения. Фактически Лондон хотел одновременно “быть в Европе”, не находиться под “властью Европы” и лидировать в Европе.

Реальный шанс выйти из этого заколдованного круга был при Т. Блэре, который понимал: для того чтобы играть лидирующую роль в Европе, нужно быть в “центре Европы”, то есть участвовать в центральных проектах ЕС, прежде всего в еврозоне. Блэр аргументировал свою позиции, апеллируя к истории: хотя британцы никогда не верили в успех интеграции, "ЕС всегда преуспевал и будет преуспевать" [Blair, 2001]. Именно поэтому следует наконец в полной мере присоединиться к этому успешному проекту. По иронии судьбы, именно при Блэре стали заметны первые системные проблемы Евросоюза: провал Конституции ЕС, а чуть позже разразились кризис еврозоны и миграционный кризис. В итоге политика Лондона вернулась к традиционному поиску условий, которые позволили бы одновременно быть внутри и вне Европы.

По мнению Д. Кэмерона референдум должен был зафиксировать итоги пересмотра условий членства Великобритании в ЕС, “положить конец 40 годам политических пререканий” [Major, 2013]. Это сомнительно, поскольку никакой референдум не может устранить глубокий раскол внутри британского общества. Референдум 1975 г. не помешал евроскептикам сделать из ЕС “козла отпущения”, ответственного за провалы национальной политики и даже за глобальную рецессию [Howe, 1984: 187].

Положительный итог референдума 2016 г. не остановил бы развитие ЕС; очень скоро евроскептики получили бы возможность сказать, что народ голосовал за членство в “другом ЕС”, а теперь ЕС снова изменился и навязывает Великобритании те правила, на которые ни народ, ни парламент не давали своего согласия.

Отрицательный итог референдума 2016 г. также не станет точкой в отношениях между Великобританией и ЕС. Как отметила Т. Мэй, “мы покидаем Европейский Союз, но мы не покидаем Европу" [Мау, 2017].

Сегодня Великобритания ведёт сложные переговоры о формате будущих отношений в ЕС. Завтра британскому обществу предстоят долгие дискуссии о собственной идентичности, а политикам - выработка новой внешнеполитической стратегии, продолжение поисков своей роли в современном мире. Решение выйти из состава ЕС никоим образом не отменяет того факта, что Евросоюз, будучи важнейшей политической и экономической организацией в Европе, останется наиболее важным экономическим, а также внешнеполитическим партнёром Великобритании. Никакой референдум “не сможет вырвать ЕС из Британии” [Oliver, 2015: 91].

Несмотря на планируемый развод, отношения продолжаются.

Современная Европа, 2018, №6 
Список литературы

Бабынина Л.О. (2012) Гибкая интеграция в Европейском Союзе: теория и практика применения. Москва, УРСС. 304 с.

Грант Ч. (2002). Делор. Дом который построил Жак. М.: Московская школа политических исследований. $472 \mathrm{c}$.

Громыко Ал.А. (2005) Внешняя политика Великобритании: от империи к “осевой державе” // Космополис. № 1. 2005. С. 20-33.

Дилеммы Британии: поиск путей развития. (2014) / Под ред. Ал.А. Громыко (отв. ред.), Е.В. Ананьевой. М.: “Весь Мир”. 2014. 480 с.

Европейская интегращия (2016). Учебник. / Под ред. О.В. Буториной (отв. ред.), Н.Ю. Кавешникова. 2-е изд. - М.: Издательство “Аспект Пресс", 2016. 736 с.

Кавешников Н.Ю. (2015) Методы управления в Европейском Союзе // Мировая экономика и международные отношения, № 8, 2015. С. 49-60.

Кавешников Н.Ю. Матвеевский Ю.А. (2017). Европейский Союз: история, институты, политика. - М.: Издательство “Аспект Пресс”, 2017. 320 с.

Кавешников Н.Ю. (2018) Великобритания и Европейский Союз: долгая история развода. Статья 1. Европейский вопрос // Современная Европа, № 5, 2018. С. 5-16.

Капитонова Н.К., Романова Е.В. (2016) История внешней политики Великобритании. Учебник. М.: Международные отношения, 2016. -840 c.

Монне Ж. (2001). Реальность и политика: мемуары. - М.: Московская школа политических исследований. 664 с.

Тэтчер М. (2003) Искусство управления государством. Стратегии для меняющегося мира. / Пер. с англ. - М.: Альбина Паблишер, 2003. 504 с.

\section{References}

Acheson D. (1963) Our Atlantic Alliance. Speech at West Point, 5 December 1962. Vital Speeches. Vol. XXIX. No. 6. P. 162-166. https://www.vsotd.com/issue/1963-6/our-atlantic-alliance Accessed 31 July 2018.

Babynina L.O. (2012) Gibkaya integratsiya v Evropeiskom soyuze: teoriya i praktika primeneniya [Flexible Integration in the European Union: Theory and Practice]. Moscow, URSS. 304 p.

Blair T (2001) Speech to the European Research Institute. Birmingham, 23 November 2001. https://www.theguardian.com/world/2001/nov/23/euro.eu1_Accessed 31 July 2018.

Butorina O.V., Kaveshnikov N.Yu. (eds). (2016). Evropeiskaya integratsiya [European Integration]. Moscow, Aspekt Press. 736 c.

Cameron D. (2013) The future of the EU and the UK's relationship with it. Speech. 23 January 2013. https://www.theguardian.com/politics/2013/jan/23/david-cameron-eu-speech-referendum Accessed 31 July 2018.

Cameron D. (2015) Chatham House speech on Europe. 10 November 2015 https://blogs.spectator.co.uk/2015/11/full-text-david-camerons-chatham-house-speech-on-europe/ Accessed 31 July 2018.

Churchill W. (1930). "The United States of Europe". The Saturday Evening Post, 15 February 1930.

Churchill W. (1946) A speech at Zurich University. 19 September 1946. https://rm.coe.int/16806981f3 Accessed 07 December 2018.

Cooper R. (2012). 'Britain and Europe'. International Affairs. Vol. 88. No. 6. P. 1191-1203.

Daddow O. (2012) 'The UK media and 'Europe': from permissive consensus to destructive dissent'. International Affairs. Vol. 88 No. 6. P. 1219-1236.

George S. (2000) 'Britain: Anatomy of a Eurosceptic state'. Journal of European Integration. Vol. 22. No. 1. P. $15-33$.

Gifford C. (2006) 'The rise of post-imperial populism: the case of right-wing Euroscepticism in Britain', European Journal of Political Research. Vol. 45. No 5. P. 851-869.

Grant Ch. (2002). Delor. Dom kotoryi postroil Zhak [Delor. The House that Jacque Built]. Moscow, Moskovskaya shkola politicheskikh issledovanii. $472 \mathrm{~s}$.

Gromyko Al.A. (2005) "Vneshnyaya politika Velikobritanii: ot imperii k "osevoi derzhave" [Foreign Policy of the Great Britain]' Kosmopolis. № 1. S. 20-33.

Современная Европа, 2018, №6 
Gromyko Al.A., Anan'eva E.V. (eds) (2014) Dilemmy Britanii: poisk putei razvitiya [Britain's Dilemmas: in the Search of Ways of Development]. Moscow, Ves' Mir. 480 s.

Howe G. (1984). 'The future of the European Community: Britain's approach to the negotiations'. International Affairs. Vol. 60. Issue 2. P. 187-192.

Kapitonova N.K., Romanova E.V. (2016) Istoriya vneshnei politiki Velikobritanii. [History of UK Foreign Policy]. Moscow, Mezhdunarodnye otnosheniya. $840 \mathrm{~s}$.

Kaveshnikov N.Yu. (2015) 'Metody upravleniya v Evropeiskom soyuze [Methods of Governance in the European Union]'. Mirovaya ekonomika i mezhdunarodnye otnosheniya, № 8. S. 49-60.

Kaveshnikov N.Yu. Matveevskii Yu.A. (2017). Evropeiskii soyuz: istoriya, instituty, politika [European Union: History, Institutions, Policies]. Moscow, Aspekt Press. 320 s.

Kaveshnikov N.Yu. (2018) 'Velikobritaniya i Evropejskij soyuz: dolgaya istoriya razvoda. Stat'ya 1. Evropejskiy vopros [Britain and the European Union: a long history of divorce. Article 1. European issue]'. Sovremennaya Evropa, № 5. S. 5-16.

Major J. (2013) The referendum on Europe: opportunity or threat? Chatham House, London, 14 February 2013. https://www.chathamhouse.org/sites/default/files/public/Meetings/Meeting\%20Transcripts/140213Major.pdf Accessed 31 July 2018.

May T. (2017) Florence speech. 22 September 2017.

http://www.independent.co.uk/news/uk/politics/theresa-may-florence-speech-in-full-read-brexit-plan-eutalks-single-market-divorce-bill-a7961596.html_ Accessed 31 July 2018.

Monne J. (2001). Real'nost' i politika: memuary [Reality and Politics. Memoirs]. Moscow, Moskovskaya shkola politicheskikh issledovanii. $664 \mathrm{~s}$.

Oliver T. (2015). 'To be or not to be in Europe: is that the question? Britain's European question and an in/out referendum'. International Affairs. Vol. 91 No. 1. P. 77-91.

Thatcher M. (1988) The Bruges Speech. 20 September 1988.

http://www.margaretthatcher.org/document/107332 Accessed 31 July 2018.

Thatcher M. (2003) Iskusstvo upravleniya gosudarstvom. Strategii dlya menyayushchegosya mira [Statecraft: Strategies for a Changing World]. Moscow, Al'bina Pablisher. $504 \mathrm{~s}$.

Tsoukalis L. (Ed.) (1979) Greece and the European Community. Dartmouth Publishing. 172 p.

Wall S. (2008) A stranger in Europe: Britain and the EU from Thatcher to Blair. Oxford University Press. 240 p.

Wallace W. (1991) 'Foreign policy and national identity in the United Kingdom', International Affairs. Vol. 67. No 1. P. 65-80.

\section{United Kingdom and European Union: A Long History of Divorce Part 2. Awkward partner}

Author: Kaveshnikov N., Head of Department of Integration Studies, Moscow State Institute of International Relations of the Ministry of Foreign Affairs (MGIMO University). Address: 76 pr. Vernadskogo, Moscow, Russia, 119454; Leading Researcher, Institute of Europe, Russian Academy of Sciences. Address: 11-3 Mokhovaya str., Moscow, Russia, 125009. E-mail: n.kaveshnikov@inno.mgimo.ru

Abstract: The article examines the history of relations between the United Kingdom and the European Union from the 1950s to the present. The paper examines how systemic factors - the specific attitude of the UK to the design, purposes and future of the EU, a specific understanding of the basic values of integration determined the strategy and tactics of London's European policy. It demonstrates how the contradiction between London's desires to ensure independence from the EU and to influence EU policies has been growing. The paper suggests that the main parameters of London's policy towards the EU were determined by the basic features of British identity. Rooted in history, the uneasy relationship with continental Europe had transformed into a struggle against 'hegemony of the European Union'. UK as a member state tried to negotiate conditions that would allow to be both inside and outside Europe, and participate only in specific components of integration.

Key words: European Union, United Kingdom, Brexit, European integration, identity.

DOI: http://dx.doi.org/10.15211/soveurope620181829 